\title{
Laparoscopic renal biopsy
}

Author: Brazilian Society of Urology

Participants:

Antonio Silvinato*3

Wanderley M. Bernardo* $\mathbf{1 , 2}$

(iD) Anibal Wood Branco 3

Final version: January 17, 2019

1. Lecturer Professor of School of Medicine of USP; São Paulo, SP, Brasil 2. Coordinator of the Brazilian Medical Association Guidelines Program, São Paulo, SP, Brasil.wmbernardo@usp.br 3. Author e membro do Programa Diretrizes da Associação Médica Brasileira, São Paulo, Brasil * This guideline replaces the previous 2015 version.

http://dx.doi.org/10.1590/1806-9282.65.2.100

The Guidelines Project, an initiative of the Brazilian Medical Association, aims to combine information from the medical field in order to standardize producers to assist the reasoning and decision-making of doctors.

The information provided through this project must be assessed and criticized by the physician responsible for the conduct that will be adopted, depending on the conditions and the clinical status of each patient.

\section{INTRODUCTION}

The histological evaluation of the renal tissue is particularly useful for investigating and treating several types of kidney pathologies. The histopathological diagnosis provides crucial information for determining the prognosis and the ideal treatment. Amongst the general indications for kidney biopsy are kidney diseases of unknown etiology, nephrotic syndrome, proteinuria and systemic diseases with suspicion of compromised kidney function, such as systemic lupus erythematosu ${ }^{1,3}$. Although there several ways of obtaining samples of the renal tissue, the percutaneous renal biopsy (PRB) is the most widely used, since it is reliable, minimally invasive, and can be performed under local anesthesia. However, some conditions represent a contraindication for PRB, such as bleeding diathesis, morbid obesity, solitary kidney, polycystic kidney, multiple kidney cysts, uncontrolled hypertension, and previous failed attempts of $\mathrm{PRB}^{4-6}$. Under those circumstances, kidney biopsy can be performed using alternative methods, such as guided by computed tomography $(\mathrm{CT})^{7}$, with a laparoscopic approach (transperitoneal or retroperitoneal) ${ }^{4}$, and transjugulars $^{8}$. The laparoscopic renal biopsy (LRB) provides a minimally invasive approach to open biopsy, providing a direct view of the kidney.

\section{TECHNICAL ASPECTS}

Retroperitoneal operative technique

Surgery is performed traditionally under general anesthesia. Before beginning, the orogastric and vesical tubes are inserted. The patient is positioned on the right or left lateral decubitus, with the contralateral lower limb flexed and the ipsilateral extended. The upper body and limbs are immo- 
bilized with tape over the thoracic region, hip, and lower limb in order to prevent movement during the procedure. The operating table can be bent, or a small cushion can be placed under the subcostal area to improve the exposure of the kidney during the procedure. A $1.5 \mathrm{~cm}$ incision is made, inferior and distally to the 12th rib, carefully dissecting the tissues until reaching the retroperitoneum. Through that opening, the blunt digital dissection of the retroperitoneal fat to facilitate the introduction of the expander balloon, which enlarges the dissection area while achieves the hemostasis of the retroperitoneal space. A $10 \mathrm{~mm}$ trocar is inserted through the incision and, once the optical system is coupled, the insufflation of $\mathrm{CO} 2$ begins until reaching a 12-15 mmHg pressure. This procedure can be simplified by using a optical exchanger (consisting of a optical shutter with a transparent window and blunt in the distal end), which, assisted by a 0 or 30-degree lens, enters the retroperitoneum under direct view. Then, the retroperitoneal space is dissected and, with the optics, the dissection area can be enlarged towards the lower pole of the kidney. Once there is enough room under direct view, a second trocar, now of $5 \mathrm{~mm}$, is positioned to assist the procedure. The kidney dissection begins by exposing the lower pole using a Maryland instrument and scissors. After the biopsy site is chosen, with the help of laparoscopic biopsy forceps, the cold removal of a sample of about $0.5 \mathrm{~cm}$ is conducted and sent to the pathologist in saline solution. In case of doubt, the freezing analysis is used to confirm if the sample is representative. After the biopsy, the hemostasis is conducted by putting pressure on the site with gauze or bag for a few minutes. If needed, an electric or argon scalpel can be used to cauterize the incision, or the area can be covered with a homeostatic material (gelatin sponge or oxidized cellulose) or stitched using homeostatic absorbable thread. When using an argon scalpel, it is important to open the $\mathrm{CO} 2$ exit portal, since the flow of argon gas can increase abdominal pressure. If necessary, a third trocar can be placed to assist with the procedure. After 5 minutes, the retroperitoneum pressure is reduced to $5 \mathrm{mmHg}$ to verify the effectiveness of the hemostasis. If no active bleeding is observed, the incisions are sutured, and there is no need for drainage. Finally, the vesical and orogastric tubes are removed.

\section{Transperitoneal operative technique}

As with the retroperitoneal technique, all positioning and pre-op preparations are duly followed. After positioning the patient on lateral decubitus at 45 degrees on a table that provides lateralization, the table is positioned so that the patient is on horizontal decubitus. A small incision is made on the periumbilical region and, with the help of a Veress needle, the pneumoperitoneum is obtained. After reaching a pressure of $15 \mathrm{cmH} 2 \mathrm{O}$, a $10 \mathrm{~mm}$ trocar is introduced to house the camera. Then, the peritoneal cavity is analyzed. Next, the table is repositioned to the usual position, and two other $5 \mathrm{~mm}$ trocars are introduced under direct view: one at the iliac fossa area and the other at the mid-1/3 between the xiphoid appendix and the umbilical scar. Using dissection tweezers, scissors, and an electric laparoscopy scalpel, a small dissection of the retroperitoneum is conducted, exposing the lower pole of the kidney. Then, a sample of the kidney tissue is obtained using laparoscopy tweezers or a puncture needle under direct view. After the procedure, all measures previously described concerning homeostasis and to suture are meticulously observed.

When choosing an access route, trans or retroperitoneal, for a kidney biopsy, some aspects need to be taken into account, such as the preference of the surgeon, difficulty in obtaining surgical access (particularly relevant in patients with previous surgeries) and the need for concomitant evaluation of other intraperitoneal organs. Each surgical access has its advantages. As presented, when using retroperitoneal access there is no violation of the cavity and no need for mobilization of the bowels. The transperitoneal access, on the other hand, provides a larger surgical site, and the existence of references makes the procedure easier. Whatever the route is chosen, it is important to observe all the precautions to minimize the risks of the procedure, specially concerning kidney bleeding, muscle bleeding, surgical site infections, hematuria, inadvertent lesions of the intestines and other organs, and other complications, such as the absence of kidney tissue (in case of doubt, conduct a freezing biopsy). After the surgery, most patients are released from hospital within 24 hours. Patients who require oral, subcutaneous anticoagulants can receive it 24-48 hours after the procedure and, in case of intravenous therapy with heparin, the patient must be carefully observed for the possibility of bleeding at the biopsy site. Patients 
with a persistent of significant drop in hematocrit and signs of hypovolemia during the postoperative period must be evaluated using computed tomography to measure the bleeding.

\section{METHOD}

Amongst the general indications for kidney biopsy are kidney diseases of unknown etiology, nephrotic syndrome, proteinuria and systemic diseases with suspicion of compromised kidney function, such as systemic lupus erythematosus. The purpose of this guideline is to gather medical information that can assist in decision making for patients to whom the only option to obtain a viable kidney tissue sample is under direct view. It was conducted from a systematic review of the literature with no time restriction on the Medline database using the following descriptors: P: Patients to whom the only option to obtain a viable kidney tissue sample is under direct view. Laparoscopic renal biopsy (transperitoneal or retroperitoneal), C: Kidney biopsy through open access and O: Benefit or damage. The search strategy was structured as follows: (Kidney OR Kidney Diseases) AND (Biopsy OR renal biopsy OR kidney biopsy) AND (Laparoscopy OR Laparoscopic-assisted renal biopsy OR Endoscopy OR Retroperitoneal Space OR retroperitoneal laparoscopic renal biopsy) AND (Diagnosis/Broad[filter]), retrieving 1,770 papers, out of which nine were selected to answer the clinical question: Is laparoscopic renal biopsy effective and safe? The recommendations were designed by the review authors with the initial characteristic of synthesis of evidence and were submitted to validation by all authors who participated in the creation of the guidelines. The grades for recommendation used comes directly from the power available in the studies included according to Oxford ${ }^{16}$ and the Grade ${ }^{18}$ system.

\section{RESULTS}

We found no comparative studies and selected 13 series of cases; in three studies ${ }^{9-11}(\mathbf{C})$, the access used was transperitoneal and in six, retroperitone$\mathrm{al}^{4,5,12-15}(\mathrm{C})$.

\section{Transperitoneal laparoscopic renal biopsy}

In a series of cases with children (average age 8 years, [1 year and 10 months to 13 years and 7 months] with bleeding disorders or previous percutaneous biopsy failure, they were submitted to percutaneous renal biopsy assisted by transperitoneal laparoscopy (three portals). Hemostasis was performed through simple compression with gauze. The average surgery time was 35 minutes and hospitalization time was 33.5 hours. There were no intraoperative complications, and the material was considered sufficient for diagnosis in all cases by the pathologist. The ultrasonography showed no evidence of kidney bleeding or bruising ${ }^{9}(\mathbf{C})$.

In 21 patients (14 males, 7 females, average age 58 years [21-83 years]) the method of choice for kidney biopsy was the transperitoneal technique assisted by three portals and simple compression with gauze (5$20 \mathrm{~min}$. interval). The average bleeding volume was $5.5 \mathrm{ml}$ and the surgery time was $65-120$ minutes. The sample was adequate in all patients, who were able to feed and ambulate on the following day.

There were no postoperative hemorrhagic complications, and a hernia at the site of the trocar was reported three months after the surgery on a patient with multiple abdominal surgeries ${ }^{10}(\mathbf{C})$.

In another series of cases, the transperitoneal laparoscopic technique was used to conduct diagnosis biopsies on two patients with morbid obesity (BMI 51.6 and $35 \mathrm{~kg} / \mathrm{m}^{2}$ ) and one with obese (BMI $31 \mathrm{~kg} /$ $\mathrm{m} 2$ ), all with a solitary kidney. All biopsy samples were adequate, and the patients were discharged from hospital after 1.3 days on average with no significant complications ${ }^{11}(\mathrm{C})$.

\section{Retroperitoneal laparoscopic renal biopsy}

A series included 40 patients with coagulopathy (30\%), polycystic kidney, multiple renal cysts (30\%), solitary kidney (12.5\%), and morbid obesity (10\%), who underwent retroperitoneal laparoscopic renal biopsy (LRB). All the biopsies were conducted using a Trucut needle. The average intervention time was less than 1 hour, and the sample for histopathological examination was considered adequate in all cases. There was a low rate of surgical complications (7.5\%) according to the Clavien classification (little bleeding at the portal site [two cases] and post-biopsy kidney hemorrhage requiring embolization [one case $])^{12}(\mathbf{C})$.

In a series of cases, LRB was conducted on 17 patients with an average age of 8.1 years (2-12 years) using two or three trocars. The LRB was successfully performed on 15 patients (88\%), and om two cas- 
es there was a rupture of the peritoneum requiring conversion (one to open and the other to transperitoneal). There was one case of perirenal hematoma that was spontaneously resolved. The complication rate was $17.6 \%$ ( $3 / 17$ cases). The average surgery time was 65 minutes, and the average estimated blood loss was $52 \mathrm{ml}$, and the average hospital stay was 2,2 days $^{13}(\mathbf{C})$.

The authors performed 53 kidney biopsies using a retroperitoneoscopic approach; 28 patients were males and 25 females, aged between 13 months and 19 years (average of 4 years old). The biopsies were requested after the following diagnosis: nephrotic syndrome, hemolytic-uremic syndrome, hematuria, idiopathic purpura, proteinuria ${ }^{14}(\mathbf{C})$. Ten patients had kidney failure, and all biopsy samples were adequate. There was conversion to open surgery on one case due to kidney bleeding; in 51 cases, the estimated blood loss was lower than $20 \mathrm{cc}$. The average hospitalization time was 48 hours for the first 20 cases and between 24-36 for the others ${ }^{14}(\mathbf{C})$.

In a series of cases, the authors reported the results of laparoscopic kidney biopsies using retroperitoneal access performed on a single center with a total of 32 patients ${ }^{4}(\mathbf{C})$.

Later, there was a new publication with a slight change in protocol and the addition of 42 new LRBs to this series. The operative technique remained the same, but the conventional measures were evaluated to confirm the kidney tissue and ultrasonography was used during surgery in difficult cases. Sixty-four patients (29 males and 45 females, average age 45 years [3-79]) underwent LRB with the two-portal technique, due to several indications: morbid obesity, solitary kidney, coagulopathy,

\section{REFERENCES}

1. Morel-Maroger L. The value of renal biopsy. Am J Kidney Dis 1982;1:244-8.

2. Manaligod JR, Pirani CL. Renal biopsy in 1985. Semin Nephrol 1985:5:2379.

3. Donovan $\mathrm{KL}$, Thomas DM, Wheeler DC, Macdougall IC, Williams ID. Experience with a new method for percutaneous renal biopsy. Nephrol Dial Transplant 1991;6:731-3.

4. Gimenez LF, Micali S, Chen RN, Moore RG, Kavoussi LR, Scheel PJ Jr. Laparoscopic renal biopsy. Kidney Int 1998;54:525-9. PMID: 9690219

5. Shetye KR, Kavoussi LR, Ramakumar S, Fugita OE, Jarrett TW. Laparoscopic renal biopsy: a 9-year experience. BJU Int 2003;91:817-20. PMID: 12780840

6. Mukhtar Z, Steinbrecher H, Gilbert RD, Deshpande PV. Laparoscopic renal biopsy in obese children. Pediatr Nephrol. 2005;20:495-8. PMID: 15747162 failed percutaneous biopsy, kidney at a high position, and low visibility with ultrasound. The average surgery time was $123(9-261)$ minutes, and the bleeding was 67 (5-2000) $\mathrm{ml}$; the samples obtained were considered adequate for $96 \%$ of the patients. A total of $58 \%$ of the patients were discharged from hospital in less than 24 hours; as complications (13.5\% of patients) there was significant bleeding on three patients (two during and one after surgery) and a seromuscular colon lesion ${ }^{5}(\mathbf{C})$.

Using a retroperitoneal approach, the authors performed laparoscopic kidney biopsies with two portals in 20 patients aged between 2-18 years (average of 9.7 years) in whom the percutaneous needle approach was not possible due to uncontrolled hypertension, bleeding disorders, anticoagulant us, and anatomical alterations. The biopsy site was cauterized using bipolar cautery. The biopsy was performed successfully in all cases, except in one, which was converted to an open procedure. The average surgery time was 40 minutes, blood loss was minimal, and average hospital stay was 1.2 days in the postoperative period, with a return to everyday activities after 3-5 days. In one case there was a peritoneal rupture without post-operative consequences ${ }^{15}(\mathbf{C})$.

\section{Recommendation}

- Laparoscopic renal biopsy (transperitoneal or retroperitoneal) can be the first option for cases in which there is a contraindication for kidney biopsy with a percutaneous needle. (C)

- The kidney sample from the laparoscopic biopsy is adequate for the histopathological diagnosis at a rate that varies from $96 \%$ to $100 \%$. (C)
7. Kudryk BT, Martinez CR, Gunasekeran S, Ramirez G. CT-guided renal biopsy using a coaxial technique and an automated biopsy gun. South Med J. 1995; 88:543-6 PMID: 7732444

8. Fine DM, Arepally A, Hofmann LV, Mankowitz SG, Atta MG. Diagnostic utility and safety of transjugular kidney biopsy in the obese patient. Nephrol Dial Transplant 2004;19:1798-802. PMID: 15128881

9. Bastos Netto IM, Portela WS, Choi M, Filho MF, de Toledo AC, Figueiredo AA. Laparoscopic-percutaneous kidney biopsy in children--a new approach. I Pediatr Surg 2009;44:2058-9. PMID: 19853775

10. Anas CM, Hattori R, Morita $Y$, Matsukawa $Y$, Komatsu T, Yoshino $Y$, et al. Efficiency of laparoscopic-assisted renal biopsy. Clin Nephrol 2008;70:203-9. PMID: 18793561

11. Gupta M, Haluck RS, Yang HC, Holman MJ, Ahsan N. Laparoscopic-as- 
sisted renal biopsy: an alternative to open approach. Am J Kidney Dis 2000;36:636-9. PMID: 10977798

12. Repetto L, Oderda M, Soria F, Pisano F, Besso L, Pasquale G, et al. Retroperitoneal laparoscopic kidney biopsy: technical tips for a minimally invasive approach. J Endourol 2011;25:1639-42. PMID: 21942797

13. Jesus CM, Yamamoto H, Kawano PR, Otsuka R, Fugita OE. Retroperitoneoscopic renal biopsy in children. Int Braz | Urol 2007;33:536-41; discussion 541-3. PMID: 17767760

14. Luque Mialdea R, Martín-Crespo Izquierdo R, Díaz L, Fernández A, Morales $\mathrm{D}$, Cebrían ]. [Renal biopsy through a retroperitoneoscopic approach: our experience in 53 pediatric patients]. Arch Esp Urol 2006;59:799-803. PMID: 17153499
15. Caione P, Micali S, Rinaldi S, Capozza N, Lais A, Matarazzo E, et al. Retroperitoneal laparoscopy for renal biopsy in children. J Urol 2000;164:10802; discussion 1083. PMID: 10958746

16. Levels of Evidence and Grades of Recommendations - Oxford Centre for Evidence Based Medicine. Disponível em URL: http://cebm.jr2.ox.ac.uk/ docs/ old_levels. Htm

17. Moola S, Munn Z, Tufanaru C, Aromataris E, Sears K, Sfetcu R, Currie M, Qureshi R, Mattis P, Lisy K, Mu P-F. Chapter 7: Systematic reviews of etiology and risk. In: Aromataris E, Munn Z (Editors). Joanna Briggs Institute Reviewer's Manual. The Joanna Briggs Institute, 2017. Available from https://reviewersmanual.joannabriggs.org/

18. Goldet G, Howick J. Understanding GRADE: an introduction. J Evid Based Med 2013; 6:50-4. 